Final draft. Please cite the published verison in European Journal of Philosophy.

\title{
Sellars's Ontological Nominalism
}

\author{
Ryan Simonell
}

September 15, 2021

\begin{abstract}
Wilfrid Sellars is widely known for two positions that he calls "nominalism." On the one hand, there is his "psychological nominalism," according to which any awareness one might have of abstract entities-be they properties, relations, or facts-is a thoroughly linguistic affair, and so cannot be presupposed in thinking about the process of learning a (first) language. On the other hand, there is his ontological nominalism, according to which the world, as it is in itself, is fundamentally a world of concrete particulars and so does not ultimately contain such things as properties, relations, or propositionally-structured facts. Sellars clearly takes these two sorts of "nominalism" to go together. However, one of the most influential inheritors of Sellars's philosophy, Robert Brandom, thinks that they do not. Brandom endorses the former, but denies that the latter "is in the end so much as intelligible." In this paper, I articulate the connection between Sellars's psychological and ontological nominalism and draw on Brandom's own development of Sellars's functional role semantics to argue, against Brandom, that Sellars's ontological nominalism not only harmonizes with the rest of his philosophical commitments, but is actually made fully intelligible by the very aspect of Sellars's theory that Brandom himself develops.
\end{abstract}

\section{Introduction}

Wilfrid Sellars is widely known for two positions that he calls "nominalism." On the one hand, there is his idiosyncratically-dubbed "psychological nominalism," his view that any awareness one might have of abstract entities-be they properties, relations, or facts-is a thoroughly linguistic affair, to be understood in terms of one's mastery of the functional roles of corresponding linguistic expressions, and so cannot be presupposed in thinking about the process of learning a (first) language (1956; 1963b). ${ }^{1}$ On the other hand, there is his "nominalism" in the more familiar sense of 
the term, his ontological nominalism, according to which the world, as it is in itself, is fundamentally a world of concrete particulars and so does not ultimately contain such things as properties, relations, or propositionally-structured facts (1968; 1979, 41). Sellars clearly takes these two sorts of "nominalism" to go together. However, it is not clear just how they do, and one of the most influential inheritors of Sellars's philosophy, Robert Brandom, thinks that they do not. ${ }^{2}$ Brandom takes himself to be a staunch proponent of Sellars's psychological nominalism, but he is nevertheless a staunch opponent of his ontological nominalism, endorsing an ontology according to which the world is a world of propositionally-structured facts, consisting in objects being propertied and related in various ways, and explicitly doubting whether Sellars's ontological nominalism "is in the end so much as intelligible," $(2015,270)$. In this paper, I articulate the connection between Sellars's psychological and ontological nominalism and draw on Brandom's own development of Sellars's functional role semantics to argue, against Brandom, that Sellars's ontological nominalism not only harmonizes with the rest of his philosophical commitments, but is actually made fully intelligible by the very aspect of Sellars's theory that Brandom himself develops.

Here's the plan. In Section One, I lay out the basic framework in which Sellars's two "nominalism"s are to be placed. The key to making sense of Sellars's overarching nominalistic picture, I claim, is, perhaps surprisingly, making sense of his (capital " $\mathrm{p}$ ") Platonism, specifically, his distinction between "two worlds," the world of conceptual contents, understood metaphorically as "shadows" cast by our practice of using language, and the world of reality, to which that practice casting the shadows really belongs. This general picture only comes into view through a consideration of his psychological nominalism, and it is within the context of this picture that his ontological nominalism is to be placed. In the subsequent sections, I spell out the details of this picture. In Section Two, I lay out the inversion of the platonist conception of meaning, made available by his functional role semantics, that constitutes his "psychological 
nominalism," showing how Sellars manages to spell it out in such a way that it is compatible with ontological nominalism. In Section Three, I draw on Brandom's theory of properties as modal correspondents to normatively-articulated functional roles to nonmetaphorically spell out Sellars's "two worlds" picture, according to which properties are "shadows" of the norms governing the use of predicates. In Section Four, I criticize Brandom as falling prey to a version of the "Myth of the Given," taking knowledge of the categorial structure of the world to come for free, just by learning a language with a certain syntactic structure, thus mistaking the "shadows" cast by a linguistic practice for the reality to which the practice responsible for casting the shadows belongs. It is this possible divergence between the categorial structure of reality and the logical structure of our language that opens the door for Sellars's ontological nominalism, and, in Sections Five and Six, I respond to Brandom's two main challenges to Sellars's nominalism, the first semantic and the second ontological, to show how Sellars really is able to coherently walk through it. In response to Brandom's semantic challenge, I show how Sellars's functional role semantics, developed by Brandom, enables him to think of the meanings of assertions entirely in terms of what one does in making those assertions amounts to, without appealing to any abstract contents one says. In response to Brandom's ontological challenge, I show how Sellars's late process ontology enables him to think of the world, as it is in itself, as a world solely of particulars-not particular things, but particular happenings, some of which are identifiable as the very doings that account for the appearence of the "world" of conceptual contents. The result is a nominalist picture with a systematic unity to which no other philosopher can lay claim.

\section{Sellars's Platonic Nominalism}

Ontological nominalism is the claim that the world, as it is in itself, consists solely of concrete particulars, and so does not contain such things as properties or re- 
lations, which are both abstract and general, or, consequently, propositions and propositionally-structured facts, at least insofar as such things depend for their existence on such things as properties or relations. ${ }^{3}$ Wilfrid Sellars has done as much work as anyone in twentieth century philosophy to make good on the nominalist thesis. Despite this, and despite his philosophical stature, his work does not have a significant place in contemporary discussions of platonism and nominalism. ${ }^{4}$ Indeed, it is not even recognized as a possibility in the vast majority of contemporary discussions. It is not hard to see why this is so. The view simply doesn't fit into contemporary discussions. In an almost literal sense, it's too big. The most notable thing about Sellars's distinctive brand of nominalism in this regard is that it actually contains the platonist picture of reality as a proper part. According to Sellars, there are properties and relations, and properties and relations are pretty much as the platonist takes them to be: abstract general things that particular things might instantiate. However, while the platonist is superficially correct in that there are properties and relations, the nominalist is ultimately correct in that there are really no properties and relations $(1979,41)$. It is this pair of claims, which may seem contradictory at first blush, that must be understood in order to make sense of Sellars's nominalistic vision. The key to understanding how these claims can fit together, I take it, is understanding Sellars's overarching (capital "p") Platonic picture.

Sellars's (capital " $\mathrm{p}$ ") Platonic picture can be understood as proceeding from an internal critique of (lower-case "p") platonism. The critique, in Sellars's (1956) terms, is that platonism almost always essentially involves an instance of the Myth of the Given. According to Sellars, platonism generally contains, at its core, the psychological thesis "that the phenomena of meaning (aboutness or reference) involves some sort of commerce (usually spoken of in terms of 'intuition,' 'apprehension' or 'awareness') between persons and abstract entities," (1963b, 442). For instance, on the platonist picture, knowing the meaning of "red" involves, as a precondition, awareness of the 
property of being red, since learning the meaning of "red," on the platonist psychological picture, is coming to know that the word "red" stands for this property. The basic epistemological question that the platonist faces is how to make sense of the "awareness" of abstract entities that we are supposed to have independently our knowledge of the meanings of linguistic expressions. This awareness is imagined by platonists to be simple and straightforward, but it is rarely noted just how much has to come by way of it. For instance, it seems that, if one knows what it is for something to be red, then one must know at least some such things as that something's being red implies that it's colored, is incompatible with its being green, and so on. This knowledge of the metaphysical structure of the space of properties to which the property of being red belongs, it seems, must be simply given through the mere awareness of the property of being red. Furthermore, it seems that knowing what it is for something to be red involves knowing such things as that something's being red is its instantiating a general property, something that other objects might instantiate, that its instantiating this property constitutes a fact, one which makes true the proposition that it is red, and several other facts about "categorial structure" to which properties belong, existing among other categorial notions such as objects, facts, and propositions. So, the platonist takes it that, through the mere awareness of properties, the metaphysical and categorial structure of the world "imposes itself on the mind as a seal imposes an image on melted wax," (1981a, 12). That, according to Sellars, is "perhaps the most basic form" $(1981 \mathrm{a}, 11)$ of the Myth of the Given. ${ }^{5}$

Now, there is significant debate in the secondary literature about what, exactly, the Myth of the Given is. I take it, however, that Sellars's term actually functions as a perfectly sufficient description of what it picks out. The Myth of the Given, in general terms, is simply any conception of knowledge of some aspect of reality as simply given to us, and intelligible only as given in this way. ${ }^{6}$ The basic problem with any instance of the Myth is that, by thinking of knowledge of some aspect of reality 
as given, we preclude ourselves from thinking of what we hold of reality in having this knowledge as something that we hold rationally. Holding something rationally requires being able, at least in principle, to put it in to question and, in response to that question, articulate the reasons for holding it. ${ }^{7}$ If something is taken to be simply given, and intelligible only as such, then knowledge of it constitutes a stopping point in the inquiry into our knowledge of reality, at which no questions can be asked. But if no questions can be asked, then no reasons can be given, and so we cannot make sense of our knowledge of what is given as rational. Accordingly, we cannot make sense of this supposedly given "knowledge" as genuinely knowledge. In other words, conceiving of knowledge of some aspect of reality as given undermines its very status as knowledge. Applying this general point to the particular instance of the Myth that concerns us here, any form of platonism involving the psychological thesis stated above is going to preclude us from being able to make sense of our knowledge of the metaphysical or the categorial structure to which properties belong as rational, and thus, as genuinely knowledge. Recognizing this issue, the move Sellars makes, following Carnap, is to invert the platonist order of explanation, taking our awareness of properties and relations to be underlain by our knowledge of the meanings of predicates, rather than the other way around. On this inverted picture, properties and relations are conceived of as "shadows" of the rules governing the use of predicates. Awareness of these entities is really nothing other than reified awareness of the rules governing the use of predicates, and so we can give an account of knowledge of them not as given but as achieved through language learning. ${ }^{8}$ Sellars thereby arrives at the opposing thesis of psychological nominalism, that "all awareness of sorts, resemblances, facts, etc. [... ] is a linguistic affair," $(1956,63)$.

Insofar as one takes the order of explanation to go in the direction that Sellars does, taking it that "ontological categories are the shadows, so to speak, of syntactical distinctions" $(1963 b, 256)$, one may well take it that there is a "world" of propositionally- 
structured facts, which are about objects that are propertied and related in various ways. It is just that this world is a shadow cast by the practice of using a language with the syntactic categories of sentences, singular terms, and 1- and n-place predicates. Insofar as we think of this world containing propositions, properties, and relations as but a shadow cast by the practice of using a language containing sentences and predicates, we do not have any positive reason to think that the reality to which the practice casting the shadow belongs is itself correctly categorized by the ontological framework that correctly categorizes the shadow it casts. This is not itself a reason to reject the claim that this categorial framework correctly categorizes the world, as it is in itself, independently of our practices of thinking and speaking, but it is a reason to be prima facie critical of the claim. To uncritically take the reality to which the practice responsible for casting the shadows belongs to be of the same categorial structure as the shadows it casts would be a mistake, indeed, an instance of the Myth of the Given. Sellars's nominalism is thus, to milk the metaphor of shadows for all it's worth, a Platonic nominalism. ${ }^{9}$ The platonist, ironically enough, is in the position of the prisoner in Plato's cave, who is aware of a world of appearances, of shadows, but mistakes that world for the real world underlying these appearances, to which the reality casting the shadows belongs.

That, in broad strokes, is the basic picture in which Sellars's ontological nominalism is to be placed. Ontological nominalism comes in as a way of characterizing reality only once psychological nominalism has brought into view the Platonic distinction between the world of appearance, understood as the world of conceptual contents conferred by our linguistic practice, and the world of reality, to which our linguistic practice really belongs. So, the view is at least cursorily intelligible. Still, does it actually work? Is there a well-oiled machine under these suggestive metaphors? I want to claim that there is. Let me turn to the details of the view in order to do just that. 


\section{Psychological Nominalism, Nominalistically Construed}

Let us start with Sellars's reaction to psychological platonism, the inversion of the order of explanation in the platonist conception of meaning that constitutes his "psychological nominalism." Recall, the psychological platonist supposes that, prior to learning a language, one becomes acquainted with not only concrete objects, but also abstract objects, and, in particular, the properties and relations instantiated by the objects with which one is acquainted. It is this psychological thesis that underlies the apparent explanatory fruitfulness of what Sellars calls "relational theories" of meaning. ${ }^{10}$ According to a relational theory of meaning, statements like the following:

1. The German word "rot" means red.

state that a relation of signifying or standing for, expressed by "means," obtains between a linguistic entity, the German word "rot," and an abstract entity, the property of being red. Thus, on a relational theory of meaning, (1) is analyzed as follows:

1a. The German word "rot" stands for the property of being red.

This relational analysis of (1) as (1a) is only theoretically illuminating insofar as it constitutes part of an "Augustinian" explanation of semantic competence (Wittgenstein 1953), according which learning a language is learning to match up words, be they names or predicates, with the entities in the world, be they concrete or abstract, that these words conventionally stand for. ${ }^{11}$ It thus involves a commitment to psychological platonism, whereby speakers have cognitive access to abstract entities such as properties and relations independently of their grasp of the meanings of predicates that can be appealed to in order to explain their grasp of these meanings. That, as we've explicated above, is an instance of the Myth of the Given. Psychological nominalism, as we've said, is a way of rejecting the Myth by inverting the psychological platonist order of explanation, thinking of knowledge of abstract entities as not underlying but, 
rather, underlain by knowledge of the meanings of linguistic expressions.

If one wishes to be a psychological nominalist, thinking of knowledge of abstract entities as underlain by knowledge of the meanings of linguistic expressions, one cannot, on pain of circularity, think of the meanings of linguistic expressions in terms of relations that these expressions stand to abstract entities. So, one must reject a relational analysis of "means" statements in one's account of semantic knowledge, supplanting it with an alternate conception of what is expressed by "means" statements such as (1). On Sellars's alternative proposal, intended to supplant the relational analysis, in uttering (1), rather than relating the German word "rot" to an entity picked out with a special sort of referential use of the English word "red," the property of being red, we are functionally characterizing the German word "rot" with a special sort of predicative use of the English word "red," characterizing the German word "rot" as an expression that plays the functional role in German that "red" plays in English. ${ }^{12}$ That is the basic way of thinking about meaning that enables the psychological nominalist inversion. To spell it out in a way that is compatible with ultimately endorsing ontological nominalism, Sellars has to make several moves in order to show how we can classify words as playing functional roles without appealing to properties in terms of which these words or their functional roles are identified or relations that these words are taken to stand in to their functional roles, showing that, strictly speaking, any talk of properties or relations is dispensable in this theory of "means" statements.

First, to make sense of the use of the phrase "the German word 'rot,"' which appears in the left half of (1), without taking it to be referring to the conjunction of properties that all inscriptions of "rot" instantiate, Sellars (1963, 630-633) analyzes the phrase "the word 'rot"' as a distributive singular term, thus reconstructing (1) as:

1b. "rot"s in German mean red.

Here, on the left side, reference is just made to "rot"s, particular inscriptions in German 
text. ${ }^{13}$ So, we can make sense of (1) as a statement about particulars, specifically, German "rot"s. What we're saying about these particulars, on Sellars's analysis, is that they play, in German, the role that "red"s play in English. ${ }^{14}$ To now classify particular inscriptions as playing these "roles" without referring to the properties that all the inscriptions that play that role have in common, Sellars introduces the convention of dot-quoting $(1963 \mathrm{a}, 1979)$. Using a language $\mathcal{L}$, one can dot-quote an expression $e$ to form a sortal term $\bullet e$ that applies to an expression $e^{\prime}$ belonging to a language $\mathcal{L}^{\prime}$ just in case $e^{\prime}$ plays the same functional role in $\mathcal{L}^{\prime}$ as $e$ plays in $\mathcal{L}$. So, speaking English, one can form the expression •red•, which is a sortal term that applies to English "red"s by definition, but also German "rot"s, Spanish "rojo"s, and any other expressions that play the same functional role in their language as "red"s play in English. ${ }^{15}$ Having introduced the convention of dot-quoting, Sellars is able to provide the following analysis of $(1 \mathrm{~b})$ :

1c. "rot"s in German are •red•s.

Crucially, on this analysis, the word "means" in (1) is analyzed not as expressing a relation, but, rather, as a specialized form of the copula (Sellars 1974, 431; 1979, 81). Accordingly, the use of "red" in (1) is understood as a predicative use, functioning to directly classify "rot"s, rather than a referential use, functioning to pick out some property to which "rot"s all stand in the meaning relation. Indeed, on this analysis, where "means" is construed as a specialized form of the copula, there is no meaning relation expressed in (1): there is just the functional classification of "rot"s as •red•s.

Of course, all of this is for naught if being a •red• just is being an expression that functions to ascribe the property of being red to things. Sellars is thus compelled to give an account of what it is for something to be a •red• that does not in any way make reference to the property of being red. This is just what the functional role semantics proposed by Sellars (1954), and developed by Brandom (1994, 2001), enables us to do. 
As Brandom spells out functional role semantics, we start with sentential roles, since the utterance of a declarative sentence is the minimal move that can be made in a language game, entitling, committing, or precluding one from being entitled to make other moves (See Brandom 1994, 141-198; 2001, 12-15). So, for instance, in making the move that one makes in uttering an " $a$ is red," where " $a$ " is some singular term of English, one commits oneself to making the move that one makes in uttering an " $a$ is colored," precludes oneself from being entitled to make the move that one makes in uttering an " $a$ is green," and so on. ${ }^{16}$ To arrive at the roles of predicates, we isolate the element of those sentential roles that stays constant as we substitute different singular terms into the sentences that play them. So, we notice that, if we take the utterance of another singular term, say " $b$, " and substitute it for the utterance of " $a$ " in any of these utterances, the normative relations between the moves made by the utterances are preserved. Thus, we can characterize utterances of " $a$ is red"s and " $b$ is red"s, as both $\bullet$ red $\bullet(x)$ s for some singular term $x$, and we can say that, for any singular term $x$, commitment to the move one makes in uttering a $\bullet$ red $\bullet(x)$ commits one to the move one makes in uttering a $\bullet$ colored $\bullet(x)$, precludes one from being entitled to the move one makes in uttering a $\bullet$ green $\bullet(x)$, and so on. ${ }^{17}$

We can now construe sentences which appear to articulate alethic modal relations between properties as covert expressions of the norms governing the use of functionally-characterized predicates. For instance

2. The property of being red is incompatible with the property of being green.

is construed as an expression of the norms governing the use of $\bullet$ red $\bullet$ s and $\bullet$ green $\bullet$ s: for any singular term $x$ of any language $\mathcal{L}$ containing such predicates, $\bullet$ red $\bullet(x)$ s are incompatible with $\bullet$ green $\bullet(x)$ s. ${ }^{18}$ Spelling out this normative notion of incompatibility in Brandomian terms, this is to say that commitment to the utterance of a $\bullet$ red $\bullet(x)$ precludes one from being entitled to the utterance of a $\bullet$ green $\bullet(x)$. Sellars takes it 
that sentences like (2), which involve talk of properties, play an important metalinguistic expressive role, enabling us to express the norms governing the correct use of predicates and sentences. ${ }^{19}$ However, he maintains that the role that this talk plays is not ultimately a descriptive one. Ultimately, in uttering sentences like (2), we are not articulating the modal relations that obtain between properties, but, rather, expressing semantic norms governing the use of functionally-characterized predicates. In uttering (2), one is expressing a normative attitude that one takes with respect to two acts, specifically, on the Brandomian analysis, an attitude of scoring anyone committed to the utterance of a $\bullet \operatorname{red} \bullet(x)$ to be precluded from being entitled to the utterance of a $\bullet$ green $\bullet(x)$. Such expressions function, ultimately, not to describe reality, but to regiment the language such that speakers' utterances of $\bullet$ red $\bullet(x)$ s, as a matter of dispositional fact, exclude their utterance of a $\bullet$ green $\bullet(x)$. Widespread conformity to and convergence in normative attitudes brings with it widespread agreement on sentences like (2), but this agreement is ultimately agreement in the scorekeeping habits reinforced by utterances of (2), not agreement on the truth of a proposition expressed by (2), since ultimately, on Sellars's picture, there is no such thing. ${ }^{20}$

\section{Supplementing the Sellarsian Story}

The above story is, while surely not the whole of the Sellarsian story, as much as Sellars explicitly gives us as far as a theory of properties in terms of functionally-characterized predicates. While I think it puts us on the right path, I don't think it's quite enough for an adequate account of properties. What is lacking is the resources to make sense of the apparently descriptive role that talk of properties plays, and, as Sellars himself says, "appearances are what give point to life-even for the philosopher," $(1979,7)$. Regardless of what the ultimate matter of reality is, (2) really does seem to state that a modal relation obtains between the property of being red and the property of being green; these properties are incompatible, in the sense something's 
instantiating the property of being red makes it impossible for it to simultaneously instantiate the property of being green. There is, it seems, a "world" to which these properties belong, in which they are related, and this world, it seems can be described with alethic modal vocabulary. Even if we want to deny this world's ultimate reality, we must nevertheless affirm its apparent reality in spelling out the Sellarsian picture. Brandom (2019), I believe, in his recent work on Hegel, gives us the resources to make sense of the apparently descriptive role of sentences like (2), enabling us to fill out the details of the world of appearances in Sellars's Platonic picture.

Brandom's account of properties starts with a distinction between what we're doing, in applying a predicate to some object, and what we're saying of that object in doing so, between the pragmatic characterization of the act of applying a predicate to an object and the semantic characterization of the content of such an act. According to Brandom, what we're doing, in uttering a $\bullet$ red $\bullet(x)$, for some singular term $x$, is making a particular sort of move in the language game, one that commits us to uttering a •colored $\bullet(x)$, precludes us from being entitled to utter a $\bullet$ green $\bullet(x)$, and so on. However, what we're saying, in uttering a $\bullet$ red $\bullet(x)$, for some singular term $x$, is something about the object that we're speaking of in uttering $x$; we're saying of this object that it has the property of being red, a property such that, if some object instantiates it, then, necessarily, it instantiates the property of being colored, it cannot possibly instantiate the property of being green, and so on. Here, we have an holistic correspondence between the normative relations of implication and incompatibility that obtain between our acts of applying predicates to objects and the alethic modal relations of implication and incompatibility that obtain between the properties that are the contents of these acts. Properties are alethically-articulated contents, sayables, which correspond, in context of this holistic correspondence, to normatively-articulated acts, doables. Brandom takes it that only by making this distinction between the aletheically-articulated contents of our predicates and the normatively-articulated acts applying these predi- 
cates can we make sense of what we're doing in performing predicative acts: ascribing properties to objects, thus representing them as being certain ways, and thus saying things that are either true or false, depending on how the things are.

This conception of the relation between what we're doing with the use of a vocabulary and what we're saying with that use can be extended to the use of conditional and modal vocabulary. For both Sellars and Brandom, in using modalized conditional expressions, one is expressing the norms governing the use of predicates. However, for Brandom, one is also articulating real relations between the properties expressed by those predicates. When one says, for instance, "If something's red, then it can't be green," what one is doing is expressing the normative incompatibility of acts of using $\bullet$ red $\bullet$ and $\bullet$ green $\bullet$, expressing the principle of scoring anyone committed to a -red $\bullet(x)$ to be precluded from being entitled to a $\bullet$ green $\bullet(x)$. However, what one is saying is that the property of being red is alethically incompatible with the property of being green; that something's instantiating the first property makes it impossible for it to instantiate the second. Brandom's way of drawing the distinction between doing and saying here gives us a clear way of maintaining both modal expressivism and modal realism, expressivism at the level of doing and realism at the level of saying (Brandom 2015b, 174-215). In making a statement such as "If something's red, then it can't be green," one is expressing a rule governing the acts of applying •red•s and -green $\bullet$ s, but one is also articulating a real relation between the contents of $\bullet$ red $\bullet$ and -green $\bullet$, between the property of being red an the property of being green. So, by Brandom's lights, we can have our expressivist cake and eat our realist one too. Now, Sellars, unlike Brandom, is not ultimately going to want to eat the realist cake; he is not ultimately a realist about the "world" of properties. ${ }^{21}$ Nevertheless, he is surely going to want to have a taste of the realist cake, if only to spit it out, since he must admit the apparent reality of the world of properties as constituting a crucial aspect of "the manifest image," (1962). Brandom's theory of properties as alethic correspondents to 
the norms governing the use of predicates provides the Sellarsian story with just the account of properties it needs here.

I take it that having made this Brandomian move, we gain a decisive advantage over Sellars's own officially stated theory of properties, enabling a fuller achievement of the aim of the theory, which is helpfully characterized by Robert Kraut (2010) as follows:

[Sellars] construes universals, propositions, and other "metaphysical" constructions as reifications of conceptual norms [...] On Sellars's view, abstract entities and relations among them provide no grounds for normativity; such entities are, rather, shadows cast by the norms themselves, (61).

I think this is indeed the view of abstract entities that Sellars is aiming at, but I do not think that he ever develops the resources required to cash out this metaphor of "shadows." A crucial feature of the metaphor at play here is that shadows are not identical to the things that cast them; they correspond in structure to these things, but they are not the same. Sellars, however, ends up endorsing the claim that properties just are functional roles of linguistic expressions. He tells us that abstract singular terms such as "redness" or "the property of being red," are "names of these roles," $(1962,37) .{ }^{22}$ But this just seems false. The property of being red, it seems, is not identical to the functional role of English "red"s. Rather, it corresponds to this role. There is a crucial difference between the functional role of English "red"s and the property of objects such that, if they instantiate it, an expression that plays this role is correctly applied to them. Brandom gives us a way of articulating this difference. The functional role of a predicate is normatively articulated, whereas the corresponding property is alethically articulated. The claim that the metaphysical entities are "shadows" of the norms governing the use of corresponding linguistic ones now becomes the thesis that the ontological entities are alethic reifications of the norms governing the use of their linguistic counterparts. In just this sense, properties are the "shadows" of the norms 
governing the use of predicates.

\section{Avoiding the Myth of the Categorially Given}

Let us note now that, though we have concerned ourselves so far with the way in which the alethically-articulated semantic contents of particular predicates and sentencesparticular properties, relations, and propositions-are shadows cast by the norms governing the use of those predicates and sentences, this claim applies just as well to the whole framework of properties, relations, and propositions, and so on. On Sellars's psychological nominalist picture, one comes to be aware of the world as a "structured logical space," consisting in objects instantiating properties and standing in relations, only through one's induction into a linguistic practice, $(1956,65-66){ }^{23}$ The categorial notions of "objects," "properties," "relations," and "propositions" are to be understood through the functional roles of their linguistic counterparts, singular terms, 1-place adjectival predicates, $n$-place relational predicates, and sentences. It is through mastering the use of expressions of these syntactic types-practically understanding their logically distinct functional roles-that one comes to have a grip on the ontological categories of objects, properties, relations, and propositions. It is in this sense that "ontological categories are the shadows, so to speak, of syntactical distinctions," (1963b, 256). ${ }^{24}$ We can now pose the following question: do these ontological categories on which we've come to have a grip through learning the sort of language that we've learned, which carve the world of conceptual contents conferred by our language at its categorial joints, carve the world, as it is in itself, at its categorial joints?

To immediately answer the above question affirmatively-to think, in absence of an argument, that the world, as it is in itself, simply must be ontologically categorized in a way that corresponds to the way our language is syntactically categorized-would be to fall prey to a form of the Myth of the Given. It would be to take knowledge of the categorial structure of world to be simply given, in this case, not to individuals, but, 
rather, to a linguistic community as a whole. According to Sellars, knowledge of the logical structure of language is sufficient for knowledge of the categorial structure of the "world" of conceptual contents conferred by that language, but it is not sufficient for knowledge of the categorial structure of world, as it is in itself. The world, as it is in itself, is completely independent from our conceptual representation of it, and there is no guarantee that the world and our conceptual representation of it map onto one another, not even in their basic structure. If there is to be a mapping between the world and our conceptual representation of it, this is something we must work to achieve, and achieving it may require actively transforming our language, right up to its very logical structure. ${ }^{25}$ We do not get knowledge of the categorial structure of world for free just by speaking a language. Knowledge of the world, as it is in itself, is not that easy. If it was, it wouldn't be knowledge of the world, as it is in itself. So, to think of knowledge of the categorial structure of the world as simply given to a linguistic community who speak a language with a certain logical structure is to preclude oneself from being able to think of this "knowledge of the world" as genuine knowledge of the world. I worry that Brandom, despite providing us with the very resources to make sense of this form of the Myth of the Given, falls prey to it himself.

According to Brandom, the world is the totality of facts, and a fact, for Brandom, is just a true proposition $(1994,333)$. So, the world consists in the totality of true propositions. Now, Brandom understands propositions in terms of their place in what he calls the "iron triangle of discursiveness," which consists in the correspondence between the semantic notion of the proposition, the pragmatic notion of assertion, and the syntactic notion of the declarative sentence $(2008,117) .{ }^{26}$ The facts that constitute the world are identified with the propositions that are true, which is to say, the semantic contents expressed by the declarative sentences such that, assertorically uttering those sentences, one takes oneself to be stating facts. So, the constituents of the world, the facts, are to be understood in terms of the declarative sentences that can be used to 
state them. Now, facts are structured. They consist, for instance, in objects being propertied and related in various ways $(1994,333)$. For Brandom, these notions of objects, properties, and relations are essentially understood in terms of their roles as constituents of facts, and so they too are to be understood as belonging in the iron triangle of discursiveness. So, the ontological categories that categorize the facts that constitute the world are to be understood in terms of the syntactic categories that categorize the sentences with which those facts are stated. By taking the syntactic structure of language and the categorial structure of the world to be two sides of the same coin (or, triangle, as he'd prefer to put it), Brandom falls prey to the Myth of the Categorially Given. ${ }^{27}$

It would take us too far afield to mount a substantive independent criticism of Brandom along these lines. ${ }^{28}$ My aim here is to make it clear where I take the fundamental difference between Brandom and Sellars to lie. There is $a$ sense in which Sellars agrees that the world is the totality of propositionally-structured facts. This point might be better put by saying that Sellars thinks there is $a$ world that is the totality of facts. The world we conceptually represent in experience, thought, and language, at least in our current stage of conceptual development, is a world of propositionally-structured facts, which are about objects that are propertied and related in various ways. Sellars maintains, however, that this world is a world of appearances, and, insofar as it exists at all, it "exists only in actual and obtainable representings of it," $(1968,49)$. In the world we conceptually represent, there exists properties and facts, which are represented by the use of predicates and sentences. However, there are no such things in the world, as it is in itself. What there is, in the world in itself, are actual and potential representings of properties. These representings are themselves particulars, which, though sortable, are not in any way general. Talk here of a representing as being a representing "of" some property, such as the property of being red, is not to be understood, on the final analysis, as relating the representing to some content that 
is represented (the thing that the representing is a representing" of"). Rather, it is to be understood as classifying the representing intrinsically as a representing. Saying this, once again, is just what rejecting the relational theory of meaning and supplanting it with the functional role theory of meaning entitles us to do. However, Brandom does not seem to think that this move can be made. I will now make it, demonstrating that it can be.

\section{Responding to the Semantic Challenge}

The basic move that Brandom makes that he takes to constitute a reason against Sellars's nominalism involves insisting, once again, that Sellars has not adequately appreciated the distinction between doing and saying. According to Brandom, Sellars has given an account of what we're doing with the use of predicates and sentences, including sentences containing nominalizations of predicates, but he has not given an account of what we're saying, and, in endorsing ontological nominalism, he precludes us from being able to give any such account. Properties, after all, are things that we say of things, and propositions are things that we say. If we reject the existence of such things, how are we going to be able to tell a story going about what it is to say that things are thus and so? Brandom thinks we won't be. He writes:

I don't see that we have the makings of a story on the ontological or the semantic side of what corresponds on the pragmatic side to saying (claiming, believing) something. If the world is a collection of particulars [...] what is one doing in saying that things are thus-and-so? How for Sellars are we to understand either the "thus and so" or the "saying that"? I am buffaloed, $(2015,270)$.

Brandom's worry is that, if the world consists in a bunch of nameables with no sayables, how could we make sense of what we're doing in saying that things are thus and so? What could we possibly be saying? The answer to this question, it seems, could only be "nothing," since, on the final picture, there are no things to be said. This is what we 
might call the "paradox of nominalism": nominalism seems to entail the paradoxical conclusion that nothing can be said.

Sellars's ingenious solution to this paradox is to say that it hinges on a crucial equivocation between "nothing" and "no thing," (1979, 41-43). ${ }^{29}$ Clearly, it would be absurd to say that, when we say of the tomato that it's red, we're saying nothing about it. Clearly, there's something we're saying of the tomato when we say of it that it's red: we're saying of it that it's red. It'd be absurd to deny that. It is not absurd, however, to deny that there is some thing that we're saying of it when we say of it that its red. The crucial move is to block the inference from "something" to "some thing." We are saying something of the tomato when we say of it that it's red; we're saying of it that it's red. However, "that it's red," while surely not meaningless, does not pick out some thing. Rather than functioning to pick out some thing that we're saying of the tomato when we say of it that it's red, "that it's red" functions to characterize what we're doing in saying of the tomato that it's red. What are we doing in saying of something that it's red? Well, we're making a particular sort of move in a language game, one that commits us to saying of the tomato that it's colored, precludes us from being entitled to say of it that it's green, and so on. Surprisingly enough, by spelling out the details of a functional role semantic theory, Brandom gives us just the account we need for us to respond to his own worry.

The root of Brandom's befuddlement here, I think, is his commitment to the Fregean distinction between content and force. Brandom takes it that when one "says that things are thus and so" there is a content-that things are thus and so- to which one attaches a force-asserting it. In other words, there is a distinction between, on the one hand, content asserted and, on the other hand, the act of asserting that content. If we endorse a functional role semantics, however, we need not think this way. I don't think Brandom should, and I don't think that Sellars, ultimately, does. On Sellars's final view, there are no such things as the contents that $p$ or that $q$, which are the 
things that are said, when one says that $p$ or says that $q$. The expressions "that $p$ " and "that $q$ " are properly understood not as picking out relata of a saying relation, but as functioning to classify sayings, intrinsically as sayings $(1969,227-228 ; 1979,72-73) .{ }^{30}$ So, there are just sayings that $p$ and sayings that $q$. These are two different sorts of doings, both identifiable as sayings in virtue of playing the role that sayings do in a linguistic practice in which they are done, and identifiable as distinct sorts of sayings in virtue of playing distinctive roles of this sort. ${ }^{31}$ For instance, one's saying that $p$ might commit one to a saying that $r$, whereas one's saying that $q$ might preclude one from being entitled to a saying that $r$. So, Brandom's development of Sellars's functional role semantics, in addition to giving us an account of the appearance of propositional contents, also enables us to do without them in our conception of the world, as it is in itself, enabling us to analyze sayings simply as doings, as makings of moves in the game of giving and asking for reasons. Just as speaking of moves in chess does not require us to speak of the "contents" of those moves, neither does speaking of moves in the game of giving and asking for reasons. In this way, Brandom gives us the resources to spell out an account of "contents" in which, strictly speaking, there are no contents. ${ }^{32}$

Now, the traditional argument for the distinction between contents asserted and acts of asserting them is the so-called "Frege/Geach problem." One canonical version of this problem involves supposedly showing that, in order to make sense of such things as the validity of modus ponens, one must appeal to propositional contents that can be expressed without being asserted. ${ }^{33}$ Consider the following application of modus ponens in schematic form:

$$
\frac{\text { If } p \text {, then } q \quad p}{q}
$$

Intuitively the first premise functions not to assert the proposition $p$ or the proposition $q$, but, rather, to assert that a relation obtains between the proposition $p$ and the proposition $q$ : if the first one is true, then so too is the second. Only in the second 
premise, where " $p$ " shows up unembedded, is $p$ not merely expressed but asserted as well. Now, the crucial thought is that, in order for the argument to be unequivocally valid, it must be the same propositional content that gets expressed without being asserted in the first premise and that gets asserted in the second premise. If that's so, there must be, in addition to acts of assertion, propositional contents that are assertable, yet detachable from the force of assertion. Accordingly, any account that aims to make sense of assertions simply as acts without appeal to any contents that are asserted, is mistaken.

If the above argument goes through, then the Sellarsian strategy I've just outlined is hopeless. However, once again, Brandom's own resources give us another way to go here. Here, it is logical expressivism that comes to the rescue. ${ }^{34}$ Once we have an expressivist account of conditionals, we can give an account of what one is doing in uttering a sentence of the form "If $p$, then $q$ " that does not any way commit us to the claim that " $p$ " and " $q$ " pick out sayables rather than mere doables. What is one doing in uttering a sentence of the form "If $p$, then $q$ "? Well, this is going to depend on the particular sort of logical expressivism that one endorses, but, to give a simple expressivist theory of conditionals just to see how the basic account is supposed to go, let us say that what one is doing, in uttering a sentence of the form "If $p$, then $q$," is expressing an attitude of permissive consequence, licensing the doing of $q$, upon the licit doing of $p .{ }^{35}$ To do this, in general terms, is to license the doing of one on thing on the basis of the licit doing of another. That itself is a doing, one that can itself be licensed from other doings, and licensing this doing from some other doing would be what one would be doing were one to utter a conditional sentence in which this conditional sentence is embedded as a consequent. In this way, we can think of the two premises, understood simply as doings of distinctive sorts, as licensing the conclusion. Of course, this is just one example, meant to show how the general strategy is supposed to work, and it would have to be worked out in many cases in order to respond to the 
Frege/Geach problem in its full generality, but there is no reason to think that it can't work for the various other cases. ${ }^{36}$

Of course, Brandom may be inclined to re-raise the initial charge here, saying that this may well be a fine account of what one is doing in uttering a sentence of the form "If $p$, then $q$," but we still need an account of what one is saying in doing that. The response, once again, is that, insofar as we're speaking of the world, as it is in itself, there is no thing that is said over and above the thing that is done. Sayings really are just doings of a certain sort, moves in the game of giving and asking for reasons, and distinctive sorts of sayings, for instance, conditional sayings, are just moves that play a distinctive sort of functional role, for instance, functioning to license the making of some move from the making of some other, but not functioning to make either of these moves itself. So, strictly speaking, there are no "things that are said" by utterances of declarative sentences, conditional or otherwise; there are only things that are done. It is Sellars's functional role semantics, developed by Brandom, that enables us to say this, maintaining without paradox that, in doing so, there is no thing we are saying, just something we are doing, a move we are making.

\section{Responding to the Ontological Challenge}

So, Sellars can make sense of what we're doing in "saying that things are thus and so" without appealing to semantic contents that are said, thus maintaining that the world, as it is in itself, does not contain any such things as properties or propositions. This, however, immediately raises the question of how we should characterize the world as it is in itself, if not in terms of the ontological categories of properties, relations, and propositionally-structured facts. Sellars is clear, of course, that the world, as he conceives of it, is fundamentally a world of particulars. The issue that Sellars needs to address, however, is how to make sense of a world of particulars as an articulated world, such that we can make sense of our scientific vocabularies, at the various 
levels of description at which science can be done, as correctly describing the world. ${ }^{37}$ Brandom rightly recognizes the basic Sellarsian strategy:

As far as I can see, Sellars is envisaging a world in which the "ones-inmany" needed to make sense of an articulated world are such as could be referred to by common nouns (sortals). That is the alternative to universals he seems to be working with, $(2015,271)$.

But Brandom doesn't see how this strategy can be made to work. Specifically, he worries that one cannot make sense of the criteria of application of supposedly unproblematic sortal terms without implicitly or explicitly appealing to problematic predicate terms, $(2015,271)$.

To consider Brandom's worry abstractly, consider a vocabulary with a set of sortals- $-S, T, U$, and so on-a set of predicate adjectives $-F, G, H$, and so on-and a set of names-a, $b, c$, and so on. Now, the reason that sortals, in addition to names, are nominalismically acceptable is that every correct use of a sortal expression, there corresponds a particular, a nameable, that is sorted by that sortal. For instance, if, pointing at something, I say, "There's an $S$," I am talking about a particular $S$, the one I pointed out. But what is it for something to be an S? That is to ask, what are the criteria for the application of this sortal expression? Brandom takes it that the only way to articulate these criteria is inferentially, and the only way one could do that is by deploying adjectival vocabulary; in addition to saying such things as, "If something's an $S$, then it's a $T$," we must say such things as, "If something is an $S$, then it is $F$," "If something is an $S$, then if it is not $G$, then it is $H$," and so on. Here, it seems that we can only articulate the content of the sortal $S$ with the use of the adjectival expressions $F, G$, and $H$, and these are ontologically problematic since they have no criteria of identity and individuation and so cannot purport to speak of particular things, but must, rather, express general ways for particular things to be. So, Sellars wants a world of particulars, but he needs a world of sorted particulars, and we can't make sense of the sorts to which these particulars belong without appealing to properties that these 
particulars have, in virtue of which they are to be sorted as they are.

Now, the obvious way to respond to an argument of this sort is to deny that the content of the sortal $S$ needs to be spelled out with the use of predicative adjectives and can be spelled out solely with the use of other sortals. It's hard, however, to see how this strategy can be made to work. One way to try to cash out what it is for something to be an $S$ in terms of other sortals is to do so mereologically, saying something such as, for something to be an $S$ is for it to be composed of a certain number of Ts. However, this strategy is surely hopeless. Being a lion, for instance, surely cannot be identified with being mereological sum of parts of a certain sort. Let me give three reasons why. First, while one could account for some of the statements articulative of the content of "lion" in this way, such as "Lions have four legs," the vast majority of the statements we make about lions, such as "Lions are tawny," "Lions are carnivorous," and so on, seem to resist any sort of mereological analysis. Second, to make matters worse, a mereological account of the criteria of application of the term "Lion" is incompatible with the criteria of identity and individuation. Something's being the same lion through some period of time is compatible with its changing its parts, through consumption and excretion, through that period of time. Finally, as if more was needed, the most basic reason a mereological account of the criteria of application of a sortal is not going to work is that it cannot be applied at the base level. If our account of what it is for something to be the sort of thing it is requires us to appeal to the things that compose it, then, if and when we reach a level of basic uncomposed things, elementary particles, say, we're not going to be able to apply our account to make sense of their being of different sorts. It is on the basis of considerations like these, I take it, that Brandom thinks that one is ultimately going to have to appeal to properties in making sense of the criteria of application of sortal terms.

Insofar as we think of the world as a world of things or objects, it's hard to see what the strategy for the Sellarsian ontological nominalist could be other than the mereo- 
logical one, and, in that case, it's quite clear that it's not going to work. ${ }^{38}$ However, Sellars's final version of nominalism, not developed until very late in his career and still only rather sketchily at that, provides a crucial response to this worry: the particulars that fundamentally constitute the world are not, in the first instance, particular things (objects), but, rather, particular happenings (processes, events, or activities). It is this final ontological framework that enables us to respond to Brandom's ontological challenge. ${ }^{39}$ I've been implicitly working in this framework here, but let me now lay it out explicitly. Happenings, on Sellars's conception of them, are particulars through and through. They're sortable, but their sortability not mediated by their instantiation of general properties. So, there may be one $\phi$-ing at one time and place and another, distinct, $\phi$-ing at a different time and place. Here, the thought is, we have two particular $\phi$-ings, both classifiable as such in virtue of what they do-the difference they make in a world of other happenings. We may say, for instance, that a $\phi$-ing at a particular time and place excludes a $\psi$-ing at that time and place, necessitates a $\chi$-ing at some other time and place, and so on. ${ }^{40}$ The world, according to Sellars's final ontological picture, is a world of such happenings, which, though particulars, regularly unfold in certain patterns, and so are classifiable as happenings of different sorts.

I have been implicitly appealing to this ontological picture in order to speak of our own discursive acts, specifically, our own languagings, abstractly characterizable as saying that $p$ s or saying that $q \mathrm{~s}$. According to the analysis proposed in the previous section, such acts are ultimately identified simply in terms of what it is to do them, in terms of their role in a linguistic practice, and so characterizable intrinsically as sayings of distinctive sorts without any appeal to distinctive propositional contents that are "said." The act of saying that $p$, on this account, is characterized simply a doing of a certain sort, identified in terms of the difference it makes among other linguistic doings, precluding or mandating them. Accordingly, one only needs to speak of particular saying that ps, characterized in terms of their linguistic roles, without needing to speak 
of any abstract propositional content picked out by the phrase "that $p$ " or some abstract relation that one stands to that propositional content that is "said." These sayings, on this conception, are simply happenings of a certain variety, identified in terms of their role among happenings of the same variety, excluding or necessitating them, where these happenings are conceived from within the practice as doings governed by normative relations of preclusive and committive consequence. Discursive beings such as ourselves can be identified as loci of happenings of this variety. So, to respond to Brandom's challenge with an example near and dear to Brandom's heart, the criteria of application for the sortal term "discursive being" to us, conceived of as those who say "We," can be articulated directly in terms of the patterns of happenings, specifically languagings, intelligible only as norm-governed doings, that unfold whenever you have one of us. ${ }^{41}$

Consider now the example of something in the world, external to ourselves and our own acts, to which we might apply this ontological picture, a particular lion, say. According to this picture, something's being a lion is not its instantiating the general kind lionhood. Rather, it is its doing what lions do, being the locus of the patterns of processes that unfold in the world whenever you have a lion. So, to be a lion is to eat gazelles, to bear live young, to reflect light with a certain frequency, and so on. In this context, the criteria for the application of the sortal term "lion" to some particular lion, conceived of in terms of the pattern of processes that unfolds whenever you have a lion, can be articulated directly in terms of these processes. Sentences that articulate the conceptual content of the expression "lion" such as "Lions are tawny," "Lions are carnivorous," "Lions have four legs," and so on, can be reconceived, according to this final ontological picture, as functioning to regiment the language such that the patterns of the use of these expressions track the patterns of processes that unfold whenever you have a lion. Speaking of the color of lions with the use of $\bullet$ tawny॰s tracks a certain pattern of processes that unfolds whenever you have a lion, speaking of the 
eating habits of lions with $\bullet$ carnivorous $\bullet$ s tracks a different one, and so on. ${ }^{42}$ This notion of linguistic items "tracking" of certain patterns in the world is understood in terms of the fact that the patterns of languagings correspond as a whole to the patterns of happenings in the world, necessitating and excluding one another as the corresponding happenings in the world do with respect to one another. With this holistic correspondence in view, we can speak of language "picturing" the world.

In Rorty's (1997) introduction to Sellars's Empiricism and the Philosophy of Mind, he describes "Sellars's attempt to revive the 'picturing' relation," as an "accidental accretion," wisely stripped off in Brandom's "cultivation" of Sellars's view, (8). We can now see that, far from being an "accidental accretion," Sellars's revival of the picturing relation is an absolutely necessary feature of his overall philosophical picture, for it is precisely the revival of this notion that enables him to maintain the notion of representational adequacy in a conception of the world consisting solely of concrete particulars. Picturing is the notion of representational adequacy belonging to the final ontological picture, contrasting with the conception of representational adequacy, endorsed by Brandom (1994) and famously championed by John McDowell (1994), according to which representational adequacy is identity between representing and represented. ${ }^{43}$ For Sellars, this McDowellian conception of representational adequacy is correct just insofar as we limit ourselves to the "world" of conceptual contents, which consists in propositionally-structured facts which may be identical to the very propositions that we take to be the case. As we've articulated above, however, this "world," a "shadow" cast by a linguistic practice with a certain structure, is crucially distinct from the real world to which the linguistic practices casting the shadow of that world belong. In order to speak of representational adequacy of a language with respect to the real world, on this final ontological picture, we need picturing. The aim of scientific inquiry is for the patterns of our scientific languagings to picture the patterns of the happenings in the world that we mean to be describing with the use of 
our scientific vocabulary. ${ }^{44}$ Modal vocabulary, deployed in the statement of the laws of the scientific image, which articulates the conceptual contents expressed by the terms of scientific vocabulary, is understood, on the final picture, as functioning to regiment the language so that it comes to picture the world. It is only through the language's becoming well-regimented through hard scientific work that it is possible to grasp the structure of the world, as it is in itself, by grasping the structure of a language that pictures it.

\section{Conclusion}

In this paper, I have focused on Brandom's criticisms of Sellars's nominalist picture, arguing that Sellars not only has the resources to respond to these criticisms, but that the key Sellarsian ideas that figure in these responses are the very ones that Brandom develops in his own work. It is perhaps worth saying, in closing, why I have not considered criticisms of Sellars's view that have arisen within the context of discussions of platonism vs. nominalism in contemporary metaphysics. The main reason for this is that there essentially are no such criticisms. Sellars's name is occassionally mentioned in contemporary discussions of platonism vs. nominalism, but a view of the form actually put forward by Sellars is not recognized as a possibility in these debates. Contemporary portrayals of nominalism, widely influenced by the work of Armstrong $(1980,1989)$, often regard "predicate nominalism" or "concept nominalism" as possible views that one might have according to which there are really no properties. ${ }^{45}$ Though Sellars's own brand of nominalism could be described as a sophisticated version of both "predicate" and "concept" nominalism, what it means to use these terms in application to his view can only be appreciated once his philosophical system is on the table, and nothing like his system is ever considered in contemporary discussions of "predicate" and "concept" nominalism. Brandom at least attempts to come to terms with the key elements that distinguish Sellars's form of nominalism. However, as I have argued 
here, even he fails to get the full picture into view. Once we do have the full picture in view, we can draw a surprising conclusion about the relationship between the work of Brandom and the work of Sellars, one that does bear, albeit indirectly, on contemporary discussions.

Brandom describes his work as "post-Sellarsian." ${ }^{46}$ However, Sellars' nominalist picture of the world, as I've articulated it, actually contains Brandom's idealist picture of the world as a world of conceptual contents, as a proper part. Sellars's nominalism therefore goes beyond Brandom's form of idealism in locating it as one aspect of a larger "two worlds" picture of reality. Accordingly, it can be described as "post-Brandomian." 47 Highlighting the respect in which Sellars may be said to be a post-Brandomian helps to bring out the contemporary relevance of of his work if one considers the way in which the vast majority of contemporary philosophy can, arguably, be described as "pre-Brandomian." Brandom's account of conceptual content goes beyond the psychological platonist picture that is endorsed by the vast majority of contemporary philosophers of mind and language, avoiding the form of the Myth of the Given to which these philosophers fall prey. Most contemporary philosophers of mind and language take properties and relations to be mind-independent abstract entities that can be appealed to in the context of a theory of linguistic competence. ${ }^{48}$ As explicated above, this, according to Sellars, implicates them in a form of the Myth of the Given. Though, as I've argued here, Brandom fails to fully extricate himself from the Myth, he does overcome this form of the Myth. So, analytic philosophy must make it into its Brandomian stage before it can enter into its Sellarsian one. That, of course, is a very bold claim, and it would go well beyond the scope of this paper to systematically substantiate it. ${ }^{49}$ Still, I hope I have said enough here to demonstrate the contemporary philosophical relevance of Sellars's nominalistic picture. ${ }^{50}$ 


\section{Notes}

${ }^{1}$ By calling the dubbing of this view "nominalism" idosyncratic, I mean specifically with respect to contemporary uses. It's not particularly idosyncratic with respect to the original, medieval use of the term.

${ }^{2}$ I focus on Brandom here because of his philosophical stature and critical engagement with Sellars, but it's worth noting that even the most close and careful interpreters of Sellars's work tend to downplay the extent to which Sellars's nominalism really does involve a commitment to ontological nominalism. Willem deVries (2011), for instance, writes

Sellars often described his realistic naturalism as 'nominalistic,' but the point is not so much to deny that there are abstracta as to tell us what language that uses abstract singular terms is doing for us and how differently it functions from language using concrete singular terms.

On the account I'm articulating here, it is a crucial feature of Sellars's realistic naturalism that there really are no such things as abstracta, and much of the point of telling us how abstracta-talk functions differently than genuine descriptive talk is to entitle us to this claim. A notable exception to this trend is Joanna Seibt (1990, 2000), puts Sellars's ontological nominalism front and center. Much of Seibt's work is congenial to what I am doing here, though the overarching "two worlds" picture developed here, in which I frame Sellars's nominalism, is not to be found in Seibt's reconstruction.

${ }^{3}$ In what follows I will think of propositions as entities which represent objects as instantiating properties or standing in relations, bracketing the question of whether of what an alternate notion of proposition or fact that does not depend on properties or relations could be.

${ }^{4}$ Unlike that of, say, Armstong or Lewis. Cowling's (2016) recent book on abstract entities, for instance, contains no reference to Sellars, and neither does Rodriguez-Pereyra's (2015) Stanford Encyclopedia article on nominalism in metaphysics.

${ }^{5}$ Sellars makes this claim, specifically, about the categorial structure of the world. The idea that the metaphysical structure of the world imposes itself on the mind in this way is presumably a less basic form of the Myth, but the two, in this case, go hand in hand.

${ }^{6}$ This way of speaking of the Myth of the Given is quite different than what you'll get in most commentators, who take the Myth of the Given to be something much more specific, involving the idea that non-conceptual awareness could serve as a rational basis for our conceptual judgments (deVries 2011; Bonevac 2007, deVries and Triplett 2000, xxv-xxvi; Brandom 1997, McDowell 1994). On the reading developed here, such an idea is an instance of the Myth, but just because it implicitly involves the idea that knowledge of the structure of experienced reality, as grasped through a conceptual understanding of that reality, is simply given. The reading here is closer to and owes some influence to that proposed by Williams (2009), according to which the "Myth of the Given in its general form [just is] epistemological foundationalism in its general form," (154). Kremer (M.S.) also proposes a reading along these lines.

${ }^{7}$ Thus, I take it that the core thought underlying the rejection of the Myth of the Given is expressed in Empiricism and Philosophy of Mind when Sellars tells us, "empirical knowledge, like its sophisticated extension, science, is rational, not because it has a foundation but because it is a self-correcting enterprise which can put any claim in jeopardy, though not all at once," (1956).

${ }^{8}$ Though what we have knowledge of, in having this knowledge, is not what we pre-theoretically take it to be.

${ }^{9}$ That Sellars's basic picture, in which his ontological nominalism is to be placed, is a Platonic one, while it might seem strange, not at all surprising. Sellars describes himself (in a rather different context) as a "a card-carrying member of the Platonic tradition," going on to say "Plato wrong is usually closer to the truth than other philosophers right," $(1971,8)$.

${ }^{10} \mathrm{~A}$ brief discussion of such theories of meaning occurs in Part 6 of Empiricism and the Philosophy of Mind. More sustained discussions can be found in Sellars (1979).

${ }^{11}$ Some version of this Augustinian conception of meaning is assumed by the vast majority of contemporary semantic theorists, as will be evident from a survey of any of the more philosophically-oriented 
introductory semantics textbooks used today. For explicit defense of this conception, in connection with these contemporary semantic theories, see King (2018).

${ }^{12}$ In both of these cases, we may suppose that the special use is achieved by italicizing the word "red."

${ }^{13}$ Now, as Conant (2020, 864-947) makes clear, something's being a "rot" cannot be understood as its being a "mere mark" of a certain shape. Rather, it must be understood as a mark that is in principle capable playing the role that "rot"s do in the practice of using the German language: that is, something's being a "rot" cannot be understood apart from its, at least potentially, being a $\bullet$ red $\bullet$

${ }^{14}$ I am here simplifying the presentation in "Abstract Entities" by modifying the grammar of regularly quoted expressions to use them as common nouns, rather than following Sellars (1963a, 49) in introducing an additional notional convention-asterisk quotes-which function by explicit convention to form common nouns.

${ }^{15}$ It follows from this convention that the English sentence "The word 'red' means red" is analytically true, in the sense that it is true by linguistic convention. Essentially, what one is saying in saying this is just that "red"s function as "red"s do, which is, of course, trivially true.

${ }^{16}$ In saying that making the move one makes in uttering " $a$ is red" commits one to making the move one makes in uttering " $a$ is colored" (or, once dot-quoting is introduced, that uttering a $\bullet a$ is red• commits one to uttering an $\bullet a$ is colored $\bullet$ ), what I mean is that, in making the first move, one is committed to making the second move in the sense that if prompted one will have to make it. In other words, if one makes the first move and one refuses to make the second move if prompted, one will be in violation of the norms. See Simonelli $(2020,4-5)$ for a defense of this way of putting things.

${ }^{17}$ Moreover, we should note norms relating $\bullet$ red $\bullet$ to non-color predicates, such as that commitment to a $\bullet$ ripe $\bullet(x)$ and $\bullet$ tomato $\bullet(x)$ commits one to an $\bullet$ red $\bullet(x)$, and so on. So, in order for German "rot"s and English "red"s to both be •red• there must be more than other color terms in the language-there must be such terms as "tomatoes," "roses," and so on. There need not be a complete coincidence in these terms (for it could be that German speakers know nothing of tomatoes), but there must be at least some substantial overlap. I leave aside, for the purpose of simplicity here, the difficult question of how to work into the functional role semantics what Sellars $(1954,1979)$ calls "language-entry" and "language-exit" transitions.

${ }^{18}$ If we are being careful, we should quantify not just over any language actually containing •red $\bullet$ and

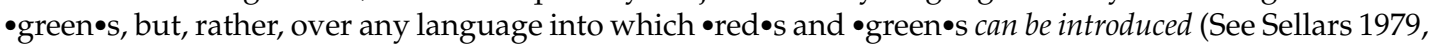
7-8 for a gesture at such a strategy). This modal qualifier is needed to respond to the worry, expressed by Himmelright (2020), that "Sellars' system cannot adequately handle cases where there are important properties without any corresponding inscriptions," (5).

${ }^{19}$ Thus, Sellars says, "Only as a last resort would I consent to expunge discourse about attributes from my vocabulary," $(1979,6)$. It's worth being clear, however, that this statement still implicitly contains the claim that it's possible to drop talk of properties, since Sellars is saying that this is what he would do, in some circumstances, as a last resort.

${ }^{20}$ This is not to say, of course, that (2) is not true. On Sellars's (1968) account, (2) is indeed true, which is to say that it is semantically assertable, given the rules of the language to which it belongs, (86-101). It's just not true in virtue of expressing a true proposition (once again, because there is no such thing).

${ }^{21}$ Genuine realism about this world, taking it to be ontologically on par with the world of objects that we are capable of bumping into would, for Sellars, amount to the "fallacy" of "projecting the rules of [our] language into the non-linguistic world," (1949).

${ }^{22}$ One might think that this is a sort of slip by Sellars, not expressive of his official view on the identity of properties. In "Abstract Entities," he says that properties are not identical to functional roles of predicates but, rather, are the functionally-characterized predicates themselves. In developing this claim, he reconstructs "the property of being red" as "the •red•," and so "the property of being red" is analyzed, not as a name, but as a distributive singular term, distributing over all the $\bullet$ red $\bullet$ s. This is, surely, a different analysis than one according to which properties are identical to functional roles, but it does not seem any better, and, moreover, the fact that Sellars equivocates here illustrates that he does not have a clear conception of exactly what identity claim he should make.

${ }^{23}$ If one looks at this part through the lens of Brandom's (1997) study guide, one will think that there's nothing especially new here. According to Brandom, the basic point of Part 7 of EPM is that one could 
not possess anything of epistemic significance independently of the possession of concepts, which is the same point that Brandom takes Sellars to be making in the opening sections of EPM where he discusses the classical sense datum theory. Brandom downplays Sellars's use of the term "structured logical space" here, saying "Sellars says 'logical' but that is just 1950s talk for 'conceptual,' which for Sellars can be parsed as 'inferential,"' (151). On my reading, there is a crucial distinction marked by the use of the term "logical" there-Sellars's concern at this point in EPM is not simply conceptual structure but specifically the structure of categorial concepts.

${ }^{24}$ This idea is spelled out in Sellars's $(1963 b, 1974)$ proposal, following Carnap, that abstract categories like properties and propositions can be introduced on the basis of analytic sentences that schematize over all the elements of a certain syntactic categories, such as "For all $p, p$ or not- $p$ " or "For all $x$ and $F, x$ is $F$ or $x$ is not $F$." Such sentences can be understood as making explicit the functional role of an expression just insofar as it belongs to the syntactic category sentence or adjectival predicate. Introducing abstract ontological categories on the basis of these sentences is a way of reifying these roles so as to be able to say what such sentences merely show. See Brandt $(2007,114-122)$ for a detailed discussion of how this Carnpian strategy figures in Sellars's thinking.

${ }^{25}$ One might wonder, given the Carnapian proposal mentioned in the previous note, whether the revisability of the basic ontological categories would require the revisability analytic sentences such as "For all $x$ and $F, x$ is $F$ or $x$ is not $F$," something which seems to be implausible. The crucial thing to note here is that the schematic letters in such tautologies range over expressions of distinctive syntactic types, and it is the very syntactic categorization of the language that is potentially subject to revision. For properties, the relevant syntactic category is adjectival predicates, schematically represented by the letter " $F$ " in the tautology just stated. Insofar as the language contains adjectival predicates, such sentences will be analytic truths-indeed, their being such is partly constitutive of there being adjectival predicates in the language. However, what is open for potential revision is the language's containing of any adjectival predicates at all. If the language were modified in such a way that nothing played this syntactic role, as I will claim it could in principle be in the final section of this paper, it would not contain the tautologies on the basis of which the category of properties could be introduced. Of course, a language could not do without sentential expressions, but note once again that I am thinking of the abstract category of propositions as representing objects as instantiating properties or standing in relations, and so the set of sentences on the basis of which this particular notion of proposition could be introduced will also include sentences involving such schematic letters as $F$ and $R$.

${ }^{26} \mathrm{It}^{\prime} \mathrm{s}$ to the point here that Brandom calls it the "iron" triangle. The metaphor, I take it, is supposed to suggest the sense of immutability - that, whatever else may change, the nexus of correlated notions that constitute the triangle cannot be shaken. By Sellars's lights, I take it, Brandom's taking there to be this sort of immutability in the core categorial semantic/pramgiatc/syntactic notions is precisely what constitutes his falling prey to the Myth of the Given. Running with the metaphor, the Sellarsian response would be to point out that even iron melts at a high enough temperature.

${ }^{27}$ One might think that Brandom has discharged the accusation of the Myth in virtue of having offered, in Chapter Six of Making It Explicit, a "transcendental deduction" of the logical structure of our language, showing that any language capable of conferring conceptual content must be syntactically categorized in the way that ours is. However, once we are a bit more careful about precisely what the correlation between syntactic categories and ontological ones is, we see that, even if Brandom's deduction works (which is a big "if"), it does not warrant an inference to the transcendental necessity of thinking of the world in terms of an object-property structure. In his writings on abstract entities, Sellars speaks of "predicates" as the linguistic correspondents of properties, but it is really specifically adjectival predicates of which he is speaking. In order for the object-property structure to be derived, rather than simply the object-kind structure, which Sellars ultimately accepts in some form, it must be specifically the use of adjectival predicates that are derived, and Brandom never produces such a derivation.

${ }^{28}$ Doing so would require demonstrating not only that the thin notion of objectivity that is developed in Making It Explicit is insufficient, but so too is the much thicker notion of objectivity developed by Brandom's Hegel in A Spirit of Trust. That is a much larger task than can be undertaken here. Still, in this regard, it's worth noting that, by Sellars's lights, even Hegel, "that great foe of 'immediacy"' $(1956,14)$ was not altogether innocent of the Myth. 
${ }^{29}$ In Naturalism and Ontology, as in several other places, the discussion of this solution is tied up with the presentation of Jumbalese, a fictional language in which there are no predicates and predication is achieved by writing singular terms in certain styles. The introduction of this fictional language is meant to show how we can think of predicates of English as auxiliary signs which function, as styles of writing do in Jumbalese, to directly classify the particulars picked out by singular terms, rather than thinking of the classifying role of predicates as mediated through the predicate's expression of some thing-a property-that is predicated of the particular in the sentence to which the predicate the singular term belong. I try to present the basic ideas here without the detour into a discussion of Jumbalese, as I think this detour would obscure the basic point here.

${ }^{30}$ Hence, an expression of the form "that $p$ " is construed "as a special sort of adverb" $(1969,227)$. While the most explicit expressions of this view are the passages in "Metaphysics and the Concept of Person" and Naturalism and Ontology, just cited, an illuminating antecedent expression of this view can be found in "Being and Being Known," where Sellars characterizes as "radically mistaken" views according to which different intellectual acts "differ not in their intrinsic character as acts but by virtue of being related to different relata. Thus, the thought of $X$ differs from the thought of $Y$ not qua act of thought, but qua related to $X$ as opposed to $Y,{ }^{\prime}(1960,41)$. Though the point is framed for thought here, the same point can be made for assertion. It's radically mistaken to think that the difference between the act of asserting that $p$ and the act of asserting that $q$ is one in which these two linguistic acts "differ not in their intrinsic character as acts, but by virtue of being directly related to different relata," two different contents, that $p$ and that $q$. On the Sellarsian alternative, the way in which the assertion that $p$ differs from the assertion that $q$ is its intrinsic character, where the intrinsic character of an act of assertion is understood in terms of its role in linguistic practice.

${ }^{31}$ For a further spelling out just how to identify a doing as a saying in virtue of its playing a distinctive sort of discursive role, see Brandom (1994, 141-198); for a summary of that account, see Wanderer (2008, 51-57).

${ }^{32}$ In recent years, several theorists, most notably Hanks $(2011,2015)$ and Soames $(2014,2015)$, have proposed "act-based" accounts of propositions, according to which propositions are act types, specifically, types of predicational acts. I am here classifying Sellars's conception of propositional content as an actbased account, but one that is distinct from contemporary act-based accounts in two crucial ways. First, contemporary act-based accounts conceptualize the act-types with which propositions are identified as properties that particular act tokens may instantiate. By contrast, on Sellars's account, there are only particulars acts, classifiable as different sorts of acts in accord with the way of thinking laid out in the following section. Second, contemporary act-based accounts take properties and relations that are predicated of objects in the acts with which propositions are identified to be abstract entities that aren't themselves acts. On the account offered here, by contrast, properties and relations are analyzed in terms of acts just as propositions are.

${ }^{33}$ There are really two versions of the Frege/Geach problem, corresponding to two papers of Geach in which he raises the Frege point. In "Ascriptivism" (Geach, 1960), he raises the problem specifically for expressivist theories of moral discourse, according to which what one's doing in saying that something is bad, for instance, is simply condemning it, rather than force-neutrally predicating badness of it. This incarnation of the Frege/Geach problem might be thought as an instance of the more general point, articulated in "Assertion" (Geach, 1965), that any theory of assertion that does not make a distinction between the content asserted and the force of asserting that content is hopeless. It is this latter, more general version of the problem that I consider here.

${ }^{34}$ The term "logical expressivm" is not completely univocal, even in a Brandomian context. Hlobil (2017), for instance, glosses logical expressivism as the thesis that logical vocabulary, when introduced to a language that does not contain logical vocabulary, but where sentences stand in relations of consequence and sets of sentences have the property of incoherence, "allows us to make explicit this consequence relation and incoherence property within the object language," (3). So construed, logical expressivism would be of little help to ontological nominalism, which claims that are no relations or properties. As I am construing it here, logical expressivism shares a closer kinship to metaethical expressivism, where it is not facts consisting in things standing in relations or having properties that are expressed by the use of logical vocabulary, but, rather, normative attitudes, which are not themselves propositional in form. 
For an explication and defense of a conception of logical expressivism more along the lines of the one I am suggesting here, see Shapiro (2018).

${ }^{35}$ Brandom $(1994,2001,2008)$ distinguishes multiple normative attitudes that conditional locutions might plausibly be thought of as expressing. Most notably, there is the distinction between attitudes of permissive consequence, according to which entitlement is attributed to the consequent, given the attribution commitment and entitlement to the antecedent, and the attitude of committive consequence, according to which commitment is attributed to the consequent, given the attribution of commitment to the antecedent. A fully developed logical expressivism is going to need to comprehend the relation between these consequence relations and the conditional locutions deployed to express them.

${ }^{36}$ One would need to provide a similar act-based analysis of disjunctive sentences, negative sentences, quantified sentences, and so on. For fuller carrying-out of general strategy with respect to these other logical expressions, see Simonelli (M.S.). Another place in which the force/content distinction has been proposed as necessary is in drawing the distinction between declarative speech acts and interrogitve speech acts, which are presumed, in the Fregean paradigm, to have the same content but distinct force (assertoric vs. interrogative). For a pragmatic analysis of the distinctive role of interrogative speech acts compatible with the nominalist strategy explicated here, see Milson (2014).

${ }^{37} \mathrm{It}^{\prime} \mathrm{s}$ worth being clear that this is an issue that arises solely with respect to the scientific image, since the manifest image is not a world consisting solely of particulars. In addition to particulars, the manifest image contains general properties and relations. The account of these denizens of the manifest image, recall, was given in Section Three. In this regard, it's important to be clear that, though Sellars's nominalist analysis of property-talk applies to the vocabulary of the manifest image, explaining utterances of sentences like "The property of being red is incompatible with the property of being green" as covert expressions of the rules governing the use of predicates, the ontology of the manifest image is not a nominalistic one; it is a platonistic one. So, there is no need to respond to this issue for the manifest image, since the particulars belonging to the ontology manifest image can be understood as being the sorts of things that they are in virtue of instantiating the general properties that they do.

${ }^{38}$ It seems that something like this strategy was tried out in one of Sellars's early paper, "On the Logic of Complex Particulars" (1949b). On the analysis proposed there "Fido is angry" is analysed as saying that there is a complex particular of which both Fido and anger are ingredients, (320-321). It's hard to see, however, what the "ingredient" relation he appeals to could be, other than some sort of mereological one. And even if something more can be said about the ingredient relation, the analysis bottoms out in primitive classificatory statements, which classify primitive particulars as being of certain primitive sorts, so we still have the basic problem with any mereological account regarding the sortability of the primitive particulars.

${ }^{39}$ Though the process ontology is not explicitly theorized until the Carus Lectures (1981), the seeds of the conception are present much earlier. For instance, in Science and Metaphysics, Sellars refers to the "natural order" as "the world of 'process' or 'becoming'," (1968, 130). Earlier than that, in "Counterfactuals, Dispositions, and the Causal Modalities," Sellars mentions that "the conception of the world as pure process" can be regarded as a "regulative ideal" of scientific inquiry, though says very little about how the world could be so-conceived, noting that "science has not yet achieved the very concepts in terms of which such a picture might be formulated," (1958). Achieving those concepts, I take it, is one of the main tasks of the Carus Lecutures. Note also that, in the Carus Lectures, the main motivation that Sellars expresses for his final ontological picture is his proposed solution to what he calls the "sensorium-body" problem, (1981c, 66). I'm bracketing that motivation here, taking it that the way in which the process ontology enables his nominalism is motivation enough. See also Seibt (2000) for a similar bracketing of this motivation.

${ }^{40} \mathrm{~A}$ proper discussion of the notions of space and time, though it would be necessary to fully spell out this nominalist picture, would require getting into aspects of Sellars's Kantianism that would take us well beyond the (already very broad) scope of this paper.

${ }^{41}$ The fact that our languagings can only be understood in normative terms, as emphasized by Brandom (1994, 623-650), is compatible with Sellars's non-reductive emergence materialism. According to Sellars, there is an explanatory direction in science, with higher-level patterns emerging out of lower level patterns, where, though the rules governing the use of vocabulary deployed to articulate the higher- 
level patterns cannot be logically reduced to the rules governing the use of the vocabulary deployed to articulate the lower-level patterns, but the higher-level vocabulary's coming to be applicable can nevertheless be causally explained through the deployment of the lower-level vocabulary (See O'Shea $2007 ; 2009,176-190)$. Sellars never got completely clear on how to think about the important transitions from lower-level patterns to higher-level patterns. However, one need not be clear on exactly how the details go in order to say that there is some series of transitions through which the world progressed from a world describable solely in the vocabulary of fundamental physics to a world describable in the normative terms in which we describe ourselves. The universe articulated by fundamental physics, comprehended as a universe of pure processes which unfold in accord with the laws of fundamental physics, constitutes the basic level of happenings out of which all the higher-level patterns of happenings, such as ourselves and our languagings, emerge.

${ }^{42}$ It's worth being clear that, according to Sellars, in our final scientific vocabulary, we're going to drop use of $\bullet$ tawny•s to speak of the colors of things, since, ultimately, colors are going to be relocated from things in the world to states of ourselves. Really, what is being pictured by the use of color vocabulary is not happenings in the world, but, rather, happenings in our head, specifically, sensory states that systematically necessitate and exclude one another in a way corresponding to the norms of committive and preclusive consequence governing the use of color terms.

${ }^{43}$ See also Hornsby (1997), who terms this conception "the identity theory of truth." Brandom's (2019) later development of the McDowellian identity theory is articulated in terms of his "bi-modal conceptual hylomorphism."

${ }^{44}$ It's worth noting that, for Sellars, all empirically meaningful vocabularies, not just the vocabulary of our final scientific theory, will picture certain features of the world. The picturing of natural languages, however, is limited to features of to structural features of the world corresponding to manifest image concepts and does not picture the reality that accounts for those features. More importantly, though picturing happens with the use of manifest image vocabulary, it is not the criterion for the correct use of that vocabulary. This fundamentally contrasts with a self-consciously nominalistic final scientific image, where we conceive of our scientific languagings as correct insofar as they picture the happenings about which we're theorizing.

${ }^{45}$ For instance, van Cleve (1994, 577-578), Rodriguez-Pereyra (2015).

${ }^{46}$ Brandom explicitly embraces a remark of Rorty's (1997) which likens the dialectical placement of Sellars and Brandom to the dialectical placement of Kant and Hegel, the analogy being that, whereas Sellars's project was an "attempt to usher analytic philosophy from out of its Humean and into it's Kantian stage" (3), Brandom work can be seen as "an attempt to usher analytic philosophy from its Kantian to its Hegelian stage," (8-9).

47 "post" here, of course, does not indicate temporal posteriority but, rather, dialectical posteriority, in the way that Brandom (2013) describes Hegel, for instance, as "post-Davidsonian."

${ }^{48}$ Once again, for an explicit statement of this theoretical orientation, see King (2018).

${ }^{49}$ That is something I have aimed to do elsewhere. See Simonelli (M.S.).

${ }^{50}$ This paper started out as something I was writing while I was sitting in on Bob Brandom's Sellars course when I was a visiting scholar at Pittsburgh. I am extremely grateful for Bob's helpful feedback at multiple stages in the process and for his enthusiasim and encouragement in my attempt to spell out a picture according to which he's on the wrong side of a fundamental philosophical dispute. I've also benefited from extensive conversations on these topics with Jim Conant, as well as helpful comments from Michael Kremer, Robert Kraut, Bill deVries, Jim O'Shea, Luz C. Seiberth, Lionel Shapiro, Michael Hicks, Preston Stovall, and an anonymous referee of this journal. Most of all, my thinking about Sellars has been shaped by many many conversations with Lawrence Dallman, who is at least as responsible for the overarching conception of Sellars's picture expressed here as I am myself. 


\section{References}

[1] Armstrong, D. M. 1980. Nominalism and Realism (Universals and Scientific Realism, Part I). Cambridge: Cambridge University Press.

[2] Armstrong, D. M. 1989. Universals: An Opinionated Introduction. Westview Press.

[3] Bonevac, Daniel. 2002. "Sellars vs. the Given." Philosophy Phenomenological Research 64, no. 1: 1-30.

[4] Brandt, Stefan. 2017. "Sellars and Quine on Empiricism and Conceptual Truth." British Journal for the History of Philosophy 25, no. 1: 108-132.

[5] Brandom, Robert. 1994. Making It Explicit. Cambridge, MA: Harvard University Press.

[6] Brandom, Robert. 1997. "Study Guide." In Empiricism and the Philosophy of Mind, 119-181. Cambridge, MA: Harvard University Press.

[7] Brandom, Robert. 2001. Articulating Reasons. Cambridge, MA: Harvard University Press.

[8] Brandom, Robert. 2008. Between Saying and Doing. Oxford: Oxford University Press.

[9] Brandom, Robert. 2013. "Some Post-Davidsonian Elements of Hegel's Theory of Agency." In Sinnkritisches Philosophieren, ed. S. Rödl and H. Tegtmeyer, 63-82. De Gruyter.

[10] Brandom, Robert. 2015. From Empiricism to Expressivism. Cambridge, MA: Harvard University Press.

[11] Brandom, Robert. 2018. “From Logical Expressivism to Expressivist Logic: Sketch of a Program and Some Implementations." Philosophical Issues 28, no. 1: 70-88.

[12] Brandom, Robert. 2019. A Spirit of Trust. Cambridge, MA: Harvard University Press.

[13] Conant, James. 2020. The Logical Alien, Part II. Cambridge, MA: Harvard University Press.

[14] Cowling, Sam. 2017. Abstract Entities. New York: Routledge.

[15] deVries, Willem. 2011. "Wilfrid Sellars." Stanford Encyclopedia of Philosophy. https://plato.stanford.edu/entries/sellars/.

[16] deVries, Willem and Timm Triplett. 2000. Knowledge, Mind, and the Given. Indianapolis: Hacket.

[17] Geach, Peter. 1960. “Ascriptivism." The Philosophical Review 69, no. 2: 221-225. 
[18] Geach, Peter. 1965. "Assertion." The Philosophical Review 74, no. 4: 449-465.

[19] Hanks, Peter. 2011. "Structured Propositions as Types." Mind, 120, no. 377: 11-52.

[20] Hanks, Peter. 2015. Propositional Content. Oxford: Oxford University Press.

[21] Himmelright, Jack. 2020. "Paraphrasing Away Properties with Pluriverse Counterfactuals." Synthese. Early Online Access: https://doi.org/10.1007/s11229-02002757-2

[22] Hlobil, Ulf. 2016. "A Nonmonotonic Sequent Calculus for Inferentialist Expressivists." In The Logica Yearbook 2015, ed. P. Arazim and T. Lákiva, 87-105. London: College Publications.

[23] Hornsby, Jennifer. 1997. "Truth: The Identity Theory." Proceedings of the Aristotelian Society 97: 1-24.

[24] King, Jeff. 2018. “W(h)ither Semantics!(?)” Nous 52, no. 4: 772-795

[25] Kraut, Robert. 2010. “Universals, Metaphysical Explanations, and Pragmatism." The Journal of Philosophy 107, no. 11: 590-609.

[26] Kremer, Michael. M.S. "The Unity of the Myth of the Given." Presented at The Wilfrid Sellars Society in January 2017.

[27] McDowell, John. 1998. "In Defense of Modesty." In Meaning, Knowledge, and Reality. Cambridge, MA: Harvard University Press.

[28] McDowell, John. 1994. Mind and World. Cambridge, MA: Harvard University Press.

[29] McDowell, John. 2009. "The Constitutive Ideal of Rationality: Davidson and Sellars." In Having the World in View, 207-220. Cambridge, MA: Harvard University Press.

[30] Milson, Jared. 2014. "Queries and Assertions in Minimally Discursive Practices." Proceedings of the Society for the Study of Artificial Intelligence and the Simulation of Behavior. Goldsmiths Press.

[31] O'Shea, James. 2007. Wilfrid Sellars: Naturalism With a Normative Turn. Cambridge: Polity Press.

[32] O'Shea, James. 2009. “On the Structure of Sellars's Naturalism with a Normative Turn." In Empiricism, Perceptual Knowledge, Normativity, and Realism: Essays on Wilfrid Sellars, ed. W. deVries, 187-210. Oxford: Oxford University Press.

[33] Rodriguez-Pereyra, Gonzalo. 2015. "Nominalism in Metaphysics." The Stanford Encyclopedia of Philosophy. https://plato.stanford.edu/entries/nominalismmetaphysics/ 
[34] Rorty, Richard. 1997. "Introduction." In Empiricism and the Philosophy of Mind, 1-12. Cambridge, MA: Harvard University Press.

[35] Sellars, Wilfrid. 1949a. "Language, Rules, and Behavior." Reprinted in Pure Pragmatics and Possible Worlds, ed. J. Sicha, 129-155.

[36] Sellars, Wilfrid. 1949b. "On the Logic of Complex Particulars." Mind 58, no. 231: 306-338.

[37] Sellars, Wilfrid. 1954. "Some Reflections on Language Games." Philosophy of Science 21, no. 3: 204-228. Reprinted in Sellars, Wilfrid. 1963. Science, Perception, and Reality, 321-358.

[38] Sellars, Wilfrid. 1956/1997. Empiricism and the Philosophy of Mind. Cambridge, MA: Harvard University Press.

[39] Sellars, Wilfrid. 1960/1963. "Being and Being Known." In Science, Perception, and Reality, 41-59. Atascadero: Ridgeview Publishing.

[40] Sellars, Wilfrid. 1962. "Philosophy and the Scientific Image of Man." In Science, Perception, and Reality. Atascadero: Ridgeview Publishing.

[41] Sellars, Wilfrid. 1962. "Truth and Correspondence." The Journal of Philosophy 59, no. 2: 29-56.

[42] Sellars, Wilfrid. 1963a. "Abstract Entities." The Review of Metaphysics 16, no. 4: 627-671. Reprinted in Philosophical Perspectives: Metaphysics and Epistemology, 4180. Atascadero: Reidgeview Publishing.

[43] Sellars, Wilfrid. 1963b. "Empiricism and Abstract Entities." Reprinted in Sellars, 1974. Essays in Philosophy and Its History, 245-286.

[44] Sellars, Wilfrid. 1968. Science and Metaphysics. Atascadero: Ridgeview Publishing.

[45] Sellars, Wilfrid. 1969. "Metaphysics and the Concept of a Person." Reprinted in Sellars, 1974. Essays in Philosophy and Its History, 214-244.

[46] Sellars, Wilfrid. 1971. “On Knowing the Better and Doing the Worse."

[47] Sellars, Wilfrid. 1974. "On the Introduction of Abstract Entities." In Essays in Philosophy and Its History, 287-317.

[48] Sellars, Wilfrid. 1974. "Meaning as Functional Classification." Synthese 27, no. 3: 417-437.

[49] Sellars, Wilfrid. 1979. Naturalism and Ontology. Atascadero: Ridgeview Publishing.

[50] Sellars, Wilfrid. 1981a. "The Lever of Archimedes." The Monist 64, no. 1: 3-36. 
[51] Sellars, Wilfrid. 1981b. "Naturalism and Process." The Monist 64, no. 1: 37-65.

[52] Sellars, Wilfrid. 1981c. "Is Consciousness Physical?" The Monist 64, no. 1: 66-90.

[53] Shapiro, Lionel. 2018. "Logical Expressivism and Logical Relations." In From Rules to Meanings: New Essays on Inferentialism, ed. O. Beran, V. Kolman, and L. Koren, 179-195. New York: Routledge.

[54] Simonelli, Ryan. 2020. "The Normative/Agentive Correspondence." Journal of Transcendental Philosophy.

[55] Simonelli, Ryan. M.S. Meaning and the World. Dissertation: University of Chicago.

[56] Seibt, Joanna. 1990. Properties as Processes. Atascadero: Ridgeview Publishing.

[57] Seibt, Joanna. 2000. "Pure Processes and Projective Metaphysics." Philosophical Studies 101: 253-289.

[58] Soames, Scott. 2014. "Cognitive Propositions," in New Thinking About Propositions. Oxford University Press.

[59] Soames, Scott. 2015. Rethinking, Language, Mind, and Meaning. Princeton University Press.

[60] Stovall, Preston. 2019. "Characterizing Generics are Material Inference Tickets: a Proof-Theroetic Analysis." Inquiry.

[61] van Cleve, James. 1994. "Predication Without Universals? A Fling with Ostrich Nominalism." Philosophy and Phenomenological Research 54, no. 3: 577-590.

[62] Wanderer, Jeremy. 2008. Robert Brandom. Stocksfield: Acumen Publishing.

[63] Williams, Michael. 2009. "The Tortoise and the Serpent: Sellars on the Structure of Empirical Knowledge." In Empiricism, Perceptual Knowledge, Normativity, and Realism: Essays on Wilfrid Sellars, ed. W. deVries, 147-186. Oxford: Oxford University Press.

[64] Wittgenstein, Ludwig. 1953/1958. Philosophical Investigations, trans. G. E. M. Anscombe. Oxford: Basil Blackwell. 